(C) 1986 ISIJ

\title{
線材・棒鋼圧延の幅広がり特性とその計算法
}

\section{Spread Characteristics and Spread Formula in Steel Bar Rolling}

Tsuneki SHINOKURA and Koichi TAKAI

\section{Synopsis:}

This paper describes the spread phenomena and geometrical models in Oval-Square, Oval-Round, Diamond-Square, Diamond-Diamond and Oval-Oval passes. The experiments have been conducted by caliber rolling of hot steel bars. The profile of stress-free surface differs for the five types of passes; in the Oval-Square, Oval-Oval and Oval-Round passes, it is approximated by circular arcs with the same radius of initial bars; in the Diamond-Diamond and Diamond-Square passes, its angle after rolling is slightly smaller than before rolling. A spread formula proposed by the authors previously has been proven to be fundamentally available to all of these five passes.

\section{1. まえがき}

近年, 線材棒鋼圧延の電算機による孔型設計, 圧延条 件設定, 圧延速度制御, シミュレーションなどが積極的 に進められているが，その利用効果を高めるためには孔 型圧延特性をより正確に記述する数式モデルの開発が不 可欠である. このよらな観点から前報1) では 4 種の圧延

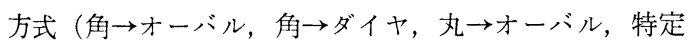
のダイヤーダイヤ）の幅広がり特性を解明し，簡便性・ 汎用性・高予測精度を兼備した新たな幅広がり式を提案 した. しかし, 線材棒鋼圧延では他にもオーバル $\rightarrow$ 角, ダ

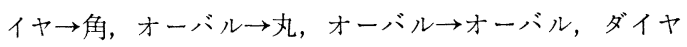
ーダイヤなど重要な压延方式があり，全パスを網羅する にはこれらにおける検討も必要である. 孔型圧延の幅広 がり式に関して従来いくつか22 6) 研究されてはいるが, 数式化の点で必ずしも上記の目的を満足していない，そ こで本研究では熱間鋼の圧延実験により，これら5種の 圧延方式の幅広がり特性を現象的に解明し, あわせて上 記新幅広がり式の適用性を検討したので報告する。

\section{2. 実 験 方 法}

ロール径 $200 \mathrm{~mm}$ の実験用孔型圧延機を用い，軟鋼 (JIS SS41) 棒と孔型の形状寸法を変えて 熱間圧延実験 を行つた. 素材は角 $\rightarrow$ オーバル, 丸ーオーバル, 角 $\rightarrow$ ダ イヤで压延したもの, 寸なわちオーバル棒やダイヤ棒を 長さ約 $220 \mathrm{~mm}$ に切断し, これらを窒素ガス中で 1050
${ }^{\circ} \mathrm{C}$ に加熱して無潤滑で圧延した． 圧延する際，材料の 倒れを防止するために入側に縦型のローラー式圧延ガイ ドを設けた. Fig. 1 に孔型の形状と寸法, Table 1 に 各孔型に対応する素材寸法 $\left(B_{0}, H_{0}, R_{s}, H_{w}, \theta_{s}\right)$, 口ルギャップ $\left(G_{0}\right)$, 圧下率 $(r)$ を示す. 出側寸法は圧延 後室温にてノギスで測定した。また，出側断面積は断面 の拡大図をプラニメーターで測定した.

\section{3. 実験結果及び数式化}

\section{1 幅広がり現象}

ここでは幅広がり側面の形状とその幾何学的近似法を
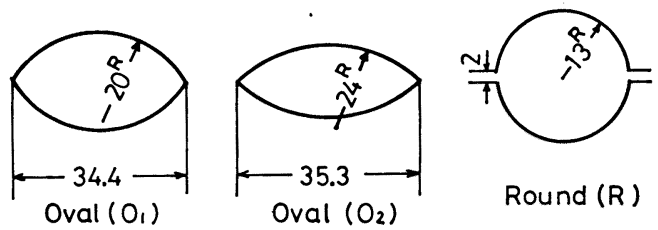

Round (R)

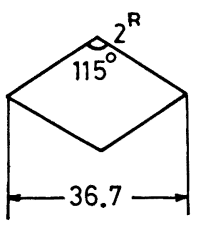

Diamond $\left(D_{1}\right)$

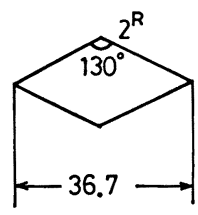

Diamond $\left(D_{2}\right)$

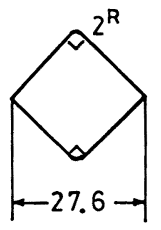

Square (S)
( ) : Symbols

Fig. 1. Shapes and dimensions of calibers (mm).

* (株) 富士電機総合研究所 (Fuji Electric Corporate Research and Development, Ltd., 2-2-1 Nagasaka Yokosuka 240-01) 
Table 1. Rolling conditions.

\begin{tabular}{|c|c|c|c|c|c|}
\hline \multirow{2}{*}{ Billet, } & \multicolumn{5}{|r|}{$(\mathrm{mm})$} \\
\hline & Caliber & $\mathrm{s}$ & 0, & $\mathrm{O}_{2}$ & $\mathrm{R}$ \\
\hline & \begin{tabular}{|l|}
$B_{0}$ \\
\end{tabular} & $15 \sim 21$ & $20 \sim 22$ & $15 \sim 21$ & $15 \sim 23$ \\
\hline & $\mathrm{H}_{0}$ & $27 \sim 37$ & $25 \sim 28$ & $22 \sim 34$ & $28 \sim 35$ \\
\hline & $R_{s}$ & 20,24 & 20 & 20,24 & 20,24 \\
\hline & $G_{0}$ & $0 \sim 1$ & $0 \sim 1$ & $0 \sim 3$ & 1,2 \\
\hline & $r(\%)$ & $15 \sim 35$ & $16 \sim 24$ & $24 \sim 45$ & $5 \sim 15$ \\
\hline \multirow[t]{5}{*}{ Billet } & Caliber & $D_{1}$ & \multicolumn{2}{|c|}{$\mathrm{D}_{2}$} & $\mathrm{~S}$ \\
\hline & Bo & $15 \sim 26$ & \multicolumn{2}{|c|}{$14 \sim 24$} & $17 \sim 28$ \\
\hline & $\mathrm{H}_{0}$ & $25 \sim 45$ & \multicolumn{2}{|c|}{$21 \sim 40$} & $28 \sim 49$ \\
\hline & $H_{w}$ & $13 \sim 45$ & \multicolumn{2}{|c|}{$12 \sim 40$} & $18 \sim 49$ \\
\hline & $\theta_{s}(\mathrm{rad})$ & $20,2.1,2.3$ & \multicolumn{2}{|c|}{$2.0,2.1,2.3$} & $2.1,2.3$ \\
\hline & \begin{tabular}{|l|}
$G_{0}$ \\
\end{tabular} & 0 & \multicolumn{2}{|c|}{0} & $0 \sim 5$ \\
\hline & $r(\%)$ & $2 \sim 37$ & \multicolumn{2}{|c|}{$12 \sim 37$} & $2 \sim 31$ \\
\hline
\end{tabular}

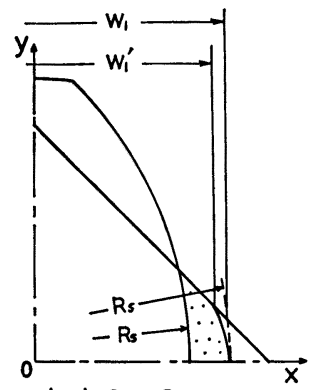

(a) $0 \rightarrow \mathrm{S}$

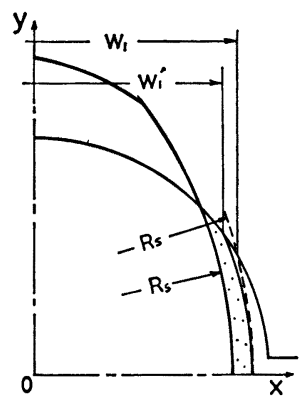

(c) $0 \rightarrow R$

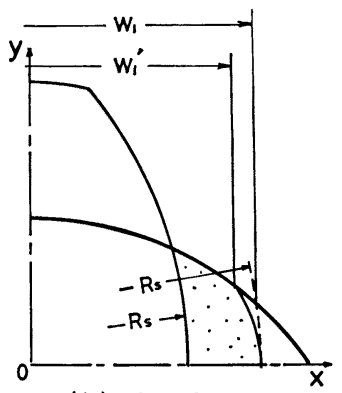

(b) $0 \rightarrow 0$
Fig. 2. Typical shapes of free side surface and its approximation in four passes.

各圧延方式ごとに述べる．いずれも側面形状は第 1 象限 で示した.

\section{$3 \cdot 1 \cdot 1$ オーバル $\rightarrow$ 角 $(\mathrm{O} \rightarrow \mathrm{S})$ 圧延}

本圧延方式は材料をガイドで押さえても圧延中倒れや すく，不安定であつた．良好な圧延品の側面形状をFig. 2 (a)に示す. 孔型の両側は空間が比較的少ないので, 自由側面はわずかである. 自由側面の形状は近似的に素 材側面の曲率半径 $\left(R_{s}\right)$ に等しい曲率の円弧で表される. 実際は側面中央部が若干膨れるので, 幾何学的に得られ

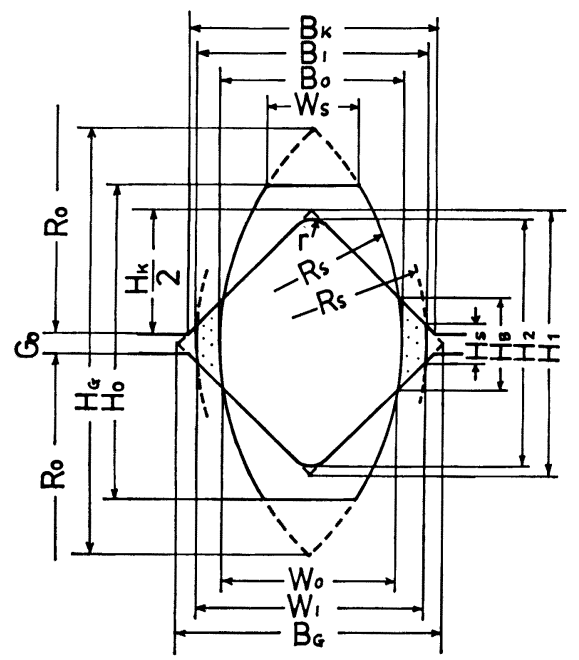

Fig. 3. Geometrical designation in Oval-Square pass.

る投影接触幅 $W_{1}$ は実測值 $W_{1}^{\prime}$ よりやや大きい.

$$
3 \cdot 1 \cdot 2 \text { オーバル } \rightarrow \text { オーバ }(\mathrm{O} \rightarrow \mathrm{O}), \text { オーバル } \rightarrow \text { 丸 }
$$
$(\mathrm{O} \rightarrow \mathrm{R})$ 圧延

これら両圧延の幅広がりは類似の現象を示す. 自由側 面の形状は低圧下率では素材側面の曲率とほぼ等しい曲 率をもつが，高圧下率では側面中央部の膨れ出しが生じ て曲率が大きくなる．両圧延の代表的側面の形状をそれ ぞれ Fig. 2(b) と（c）に示す. この場合の側面形状 の近似は素材の曲率半径 $\left(R_{s}\right)$ に等しい曲率の円弧で破 線のように表される.一般には幾何学的投影接触幅 $W_{1}$ は実測值 $W_{1}^{\prime}$ よりも若干大きくなる.

$3 \cdot 1 \cdot 3$ ダイヤ $\rightarrow$ ダイヤ $(\mathrm{D} \rightarrow \mathrm{D})$, ダイヤ $\rightarrow$ 角 $(\mathrm{D} \rightarrow \mathrm{S})$ 圧延

Fig. 2(d) は D $\rightarrow \mathrm{D}$ 圧延の側面形状を示す. 素材の 側面は前パスの孔型頂角と同じ角度をもつているが，こ

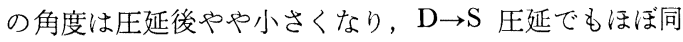
様である，そのため，側面の形状は図中のA点（材料肩 部) とB 点 (出側幅) を結ぶ直線で近似される.この場 合も一般には幾何学的投影接触幅 $W_{1}$ は央際の幅 $W_{1}^{\prime}$ よりも少し大きくなる.

\section{$3 \cdot 2$ 各圧延方式の変形モデ}

上述の側面形状の近似法に基ついて, $\mathrm{O} \rightarrow \mathrm{S}, \mathrm{O} \rightarrow \mathrm{O}$, $\mathrm{D} \rightarrow \mathrm{D}$ 各圧延方式の圧延形態を幾何学的にモデル化した のが Fig. 3〜5 である. 図中の記号 $B_{0}, H_{0}, W_{s}, H_{w}$, $H_{G}, R_{s}, \theta_{s}$ は素材の寸法や角度を表し, いずれも前パス から与えられる.ここでは $\mathrm{O} \rightarrow \mathrm{S}$ 压延の前パスは $\mathrm{S} \rightarrow \mathrm{O}$ で，O $\rightarrow \mathrm{O}$ 圧延の前パスは $\mathrm{R} \rightarrow \mathrm{O}$ または $\mathrm{O} \rightarrow \mathrm{O}$ とし た. $\mathrm{O} \rightarrow \mathrm{R}$ と $\mathrm{D} \rightarrow \mathrm{S}$ はそれぞれ $\mathrm{O} \rightarrow \mathrm{O}$ と $\mathrm{D} \rightarrow \mathrm{D}$ の特 


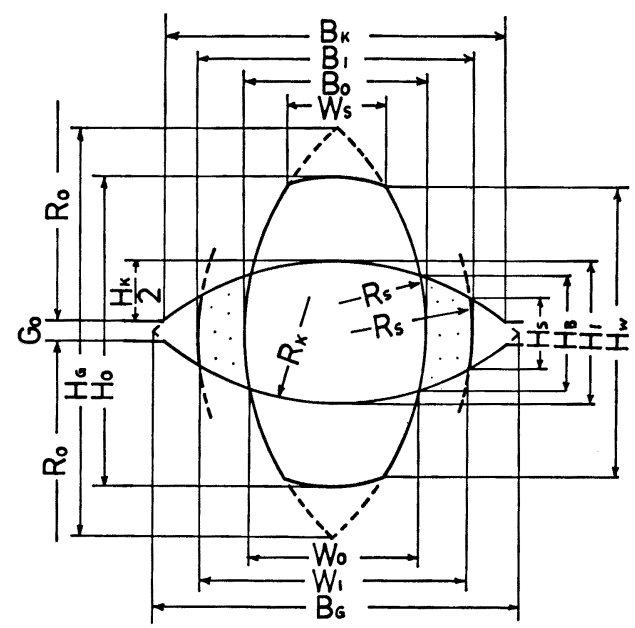

Fig. 4. Geometrical designation in Oval-Oval pass.

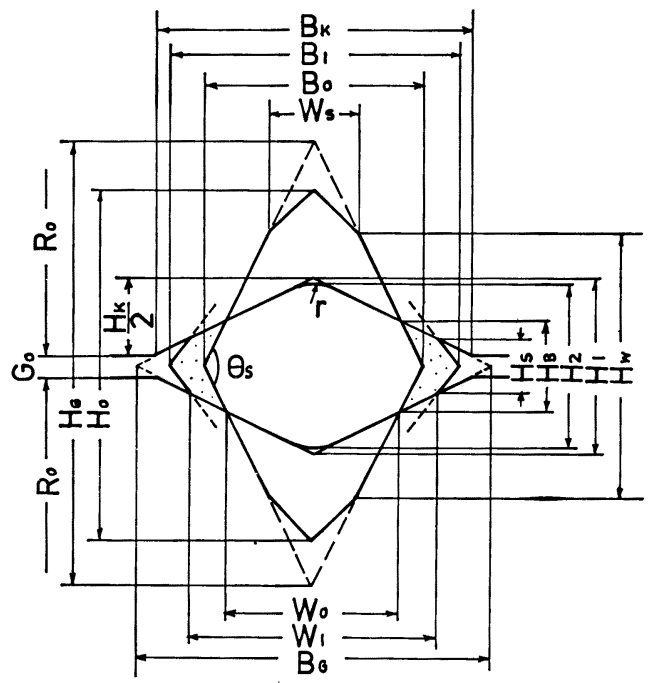

Fig. 5. Geometrical designation in DiamondDiamond pass.

殊なパスとして扱われる.なお， $\mathrm{O} \rightarrow \mathrm{O}$ の素材上下面は 簡単化のため, 曲率半径 $H_{0} / 2$ の円弧で近似しても実用 上差し支えない。

これらの変形モデルの妥当性を確認するため， $B_{1}$ の 実測値を用いて計算した最大投影接触幅 $W_{1}$ の值を実測 值と比較したところ，Fig. 6 がえられた.

各圧延方式の $W_{1}$ の計算式は次のとおりである.

イ) $\mathrm{O} \rightarrow \mathrm{S}$ では

$$
W_{1}=A+\sqrt{A^{2}-\frac{1}{2}\left(H_{1}^{2}-H_{G}^{2}\right)} \cdot
$$

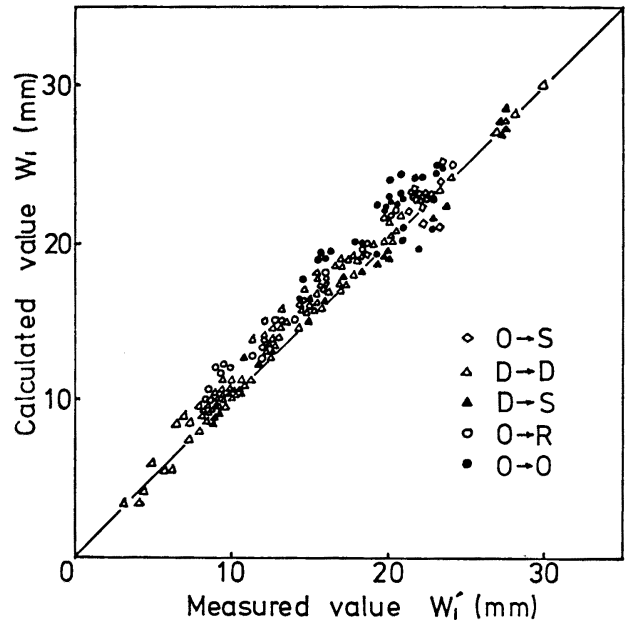

Fig. 6. Comparison of measured and calculated values of contact width $W_{1}$.

$$
A=\frac{1}{2}\left(H_{1}+B_{1}-B_{0}\right)-\sqrt{R_{s}^{2}-\frac{H_{G}^{2}}{4}}
$$

2) $\mathrm{O} \rightarrow \mathrm{O}, \mathrm{O} \rightarrow \mathrm{R}$ では

$$
W_{1}=2 \cdot R_{s}(\cos B-1)+B_{1}
$$

ただし

$$
\begin{aligned}
& B=\cos ^{-1} \frac{C+R_{s}^{2}-R_{k}^{2}}{2 \cdot R_{s} \cdot \sqrt{G}}-\cos ^{-1} \frac{R_{s}-\frac{B_{1}}{2}}{\sqrt{C}} \\
& C=\left(R_{s}-\frac{B_{1}}{2}\right)^{2}+\left(R_{k}-\frac{H_{1}}{2}\right)^{2}
\end{aligned}
$$

3) $\mathrm{D} \rightarrow \mathrm{D}, \mathrm{D} \rightarrow \mathrm{S}$ では

$$
W_{1}=\frac{B_{G} \cdot H_{1}\left(B_{1}-W_{s}\right)-B_{1} \cdot H_{w} \cdot B_{G}}{H_{1}\left(B_{1}-W_{s}\right)-B_{G} \cdot H_{w}}
$$

Fig. 6 を見ると, 実測值よりも計算值の方が若干高 めであるが，全体的にはばらつきも少なく，よく対応し ていることがわかる。

さらに，これらの近似モデルに基ついて出側断面積 $F_{1}$ を計算した．計算式は各圧延方式とも次の式を用い た。

$$
F_{1}=4\left\{\int_{0}^{W_{1} / 2} f(x) d x+\int_{W_{1} / 2}^{B_{1} / 2} g(x) d x\right\}
$$

ただし， $f(x)$ は Fig. 2 に示された $x-y$ 座標系の孔 型形状を表す関数, $g(x)$ は出側材料の側面形状（破線） を表す関数であり， $B_{1}$ は実測值， $W_{1}$ は計算值とした。 $F_{1}$ の計算值と実測值を比較したところ, Fig. 7 が得ら れ，両者はほぼ一致することが確認された。 


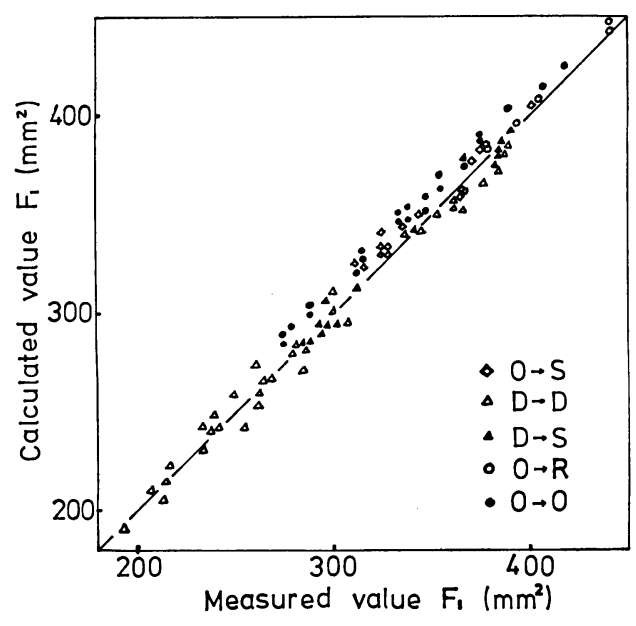

Fig. 7. Comparison of measured and calculated values of cross-sectional area $F_{1}$ of products.

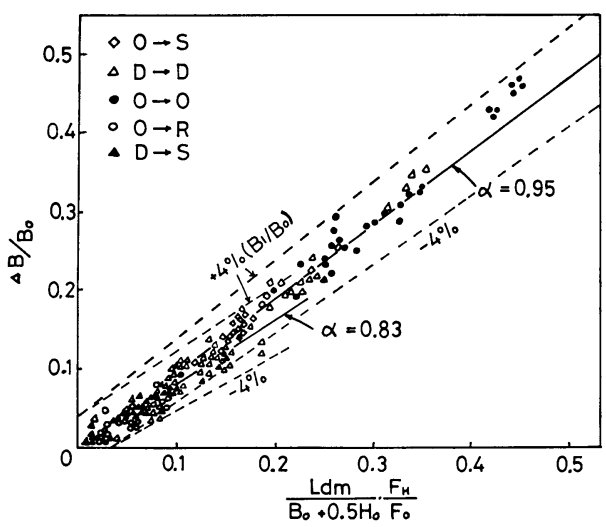

Fig. 8. Relation between spread ratio $\Delta B / B_{0}$ and parameter $\frac{L_{d m}}{B_{0}+0.5 H_{0}} \cdot \frac{F_{H}}{F_{0}}$.

\section{3 幅広がり式}

幅広がり式については前報1)で次の式を提案した。

$$
\begin{aligned}
& \frac{\Delta B}{B_{0}} \equiv \frac{B_{1}-B_{0}}{B_{0}} \equiv \alpha \cdot \frac{L_{d m}}{B_{0}+0.5 \cdot H_{0}} \cdot \frac{F_{H}}{F_{0}} \cdots \cdots(5) \\
& \text { ここに } B_{0} \text { : 入側材料幅 } \\
& B_{1}: \text { 出側材料幅 } \\
& L_{d m} \text { : 平均投影接触長 } \\
& F_{H} / F_{0} \text { : 压下率 } \\
& \alpha \text { : 係数 }(=0.83)
\end{aligned}
$$

証を行つた。 その結果を Fig. 8 に示すが, やはり良好 な直線関係がえられ，予測精度は $B_{1} / B_{0}$ で $\pm 4 \%$ であ つた. 係数 $\alpha$ は前回の $\mathrm{S} \rightarrow \mathrm{O}, \mathrm{R} \rightarrow \mathrm{O}, \mathrm{S} \rightarrow \mathrm{D}$ では 0.83 であつたが，今回は $\mathrm{O} \rightarrow \mathrm{S}, \mathrm{O} \rightarrow \mathrm{O}, \mathrm{D} \rightarrow \mathrm{D}$ では 0.95 と なつた. $\mathrm{D} \rightarrow \mathrm{S}$ と $\mathrm{O} \rightarrow \mathrm{R}$ は 0.83 であり，斎藤らての結 果とも一致した.

これまでの研究で係数 $\alpha$ は一般に統一できず，およ そ0.8〜1.0 の範囲で圧延方式や圧延条件によつて異な る值をとることがわかつた.これは（5) 式が幾何学的 因子のみで構成されており，それ以外の要因たとえば摩 擦係数，圧延温度，圧延速度およびロールと圧延材の性 状や成分などがすべて 係数 $\alpha$ に含まれているためと思 われる。

\section{4. と がき}

線材棒鋼圧延の代表的 5 種の圧延方式について，軟鋼 の熱間圧延実験を行い，幅広がり特性の現象的究明と新 幅広がり式の適用性を検討した結果，次の結論が得られ た。

幅広がり側面の形状は $\mathrm{O} \rightarrow \mathrm{S}, \mathrm{O} \rightarrow \mathrm{O}, \mathrm{O} \rightarrow \mathrm{R}$ 圧延では 円弧状， D $\rightarrow \mathrm{D}, \mathrm{D} \rightarrow \mathrm{S}$ では直線状となり，それぞれの近 似法が幾何学的に示された。新幅広がり式は今回の压延 方式にも $\pm 4 \%$ の精度で適用できるが，係数 $\alpha$ は $\mathrm{D} \rightarrow$ $\mathrm{S}$ と $\mathrm{O} \rightarrow \mathrm{R}$ では $0.83, \mathrm{O} \rightarrow \mathrm{O}$ と $\mathrm{O} \rightarrow \mathrm{S}, \mathrm{D} \rightarrow \mathrm{D}$ では 0.95 となり, 圧延方式や圧延条件によつて若干変わる ことがわかつた。

なお，これにより線材棒鋼圧延の代表的パスはすべて 網羅され,幅広がりが一貫して計算できるようになつた。

\section{交献}

1) 篠倉恒樹, 高井耕一：鉄と鋼, 67 (1981), p. 2477

2) 加藤健三, 斎藤好弘, 高橋洋一, 中川 実: 昭和 52 年度塑性加工.春季講演会論文集 $(1977)$, p. 85

3 ) 加藤健三, 斎藤好弘, 高橋洋一, 中川 実, 田中 勝博：昭和 54 年度塑性加工春季講演会論文集 (1979), p. 481

4 ) 柳本左門: 塑性と加工， 5 (1964-5), p. 315

5 ) G. Frank and $H$. Neumann: Neue Hütte, 27 (1982) 5, p. 163

6 ) $M . L$. Zaitsev and $G . V$. Anufriev: Stal in English, (1969) Aug., p. 727

7 ) 斎藤好弘, 中野 進, 高橋洋一: 昭和 54 年度塑 性加工春季講演会論文集 (1979), p. 505 